М. Е. Боровская

Белорусский государственный технологический университет

\title{
УПРАВЛЕНЧЕСКИЙ УЧЕТ КАК ЭЛЕМЕНТ СИСТЕМЫ УПРАВЛЕНИЯ ИЗДЕРЖКАМИ ЛЕСОХОЗЯЙСТВЕННОГО ПРОИЗВОДСТВА
}

Учитывая необходимость совершенствования управления издержками лесохозяйственного производства, в условиях реструктуризации деятельности лесохозяйственных учреждений, коммерциализации их деятельности главным образом за счет придания рубкам промежуточного пользования статуса коммерческих становится целесообразным организация системы их управленческого учета одновременно в лесохозяйственных учреждениях и в государственных производственных лесохозяйственных объединениях.

В современных условиях ведения комплексного лесного хозяйства управленческий учет наряду с институциализацией учета издержек лесохозяйственного производства, рентным и нормативно-бюджетным механизмом финансирования выступает основным элементом системы управления издержками лесохозяйственного производства.

Информация управленческого учета играет важную роль в системе управления лесохозяйственного учреждения, обеспечивает контроль за ходом исполнения смет доходов и расходов, за обоснованным и экономным расходованием средств в соответствии с их целевым назначением.

На основании изучения теории управленческого учета и сложившейся практики ведения аналитического учета в лесхозах представляется возможным применение интегрированной системы с использованием варианта, ориентированного на организацию учета расходов по элементам.

В статье обосновывается целесообразность организации системы управленческого учета расходов на проведение рубок промежуточного пользования, лесопродукции, полученной от их проведения, и экологических затрат.

Ключевые слова: комплексное лесное хозяйство, лесохозяйственные издержки, лесопродукция, управление, управленческий учет, финансирование.

Для цитирования: Боровская М. Е. Управленческий учет как элемент системы управления издержками лесохозяйственного производства // Труды БГТУ. Сер. 5, Экономика и управление. 2021. № 2 (250). C. 127-133.

\section{E. Borovskaya \\ Belarusian State Technological University \\ MANAGEMENT ACCOUNTING AS AN ELEMENT \\ OF THE MANAGEMENT SYSTEM COSTS OF FORESTRY PRODUCTION}

Taking into account the need to improve the management of forestry production costs, in the context of restructuring the activities of forestry institutions, commercialization of their activities mainly by giving intermediate felling the status of commercial, it becomes expedient to organize their management accounting system simultaneously in forestry institutions and in state production forestry associations.

In modern conditions of integrated forestry, management accounting, along with the institutionalization of accounting for forestry production costs, the rent and regulatory budgetary financing mechanism is the main element of the forestry production cost management system.

Management accounting information plays an important role in the management system of a forestry institution, provides control over the implementation of estimates of income and expenses, for a reasonable and economical spending of funds in accordance with their intended purpose.

Based on the study of the theory of management accounting and the established practice of conducting analytical accounting in leshozes, it is possible to use an integrated system using an option focused on organizing cost accounting by elements.

The article substantiates the feasibility of organizing a management accounting system for the costs of intermediate felling, timber products obtained from their implementation and environmental costs.

Key words: integrated forestry, forestry costs, forest products, management, management accounting, financing.

For citation: Borovskaya M. E. Management accounting as an element of the management system costs of forestry production. Proceedings of BSTU, issue 5, Economics and Management, 2021, no. 2 (250), pp. 127-133 (In Russian). 
Введение. В системе управления лесохозяйственным производством важную роль играет учетная информация, так как по своей сути бухгалтерский учет является управленческим, он предоставляет данные для анализа и контроля за исполнением смет, за экономным расходованием средств в соответствии с целевым назначением.

В условиях реструктуризации деятельности лесохозяйственных учреждений, коммерциализации их деятельности главным образом за счет придания рубкам промежуточного пользования (РПП) статуса коммерческих необходимы изменения и в системе учета. Так как действующая система бухгалтерского учета скована жесткой регламентацией, решению данной проблемы будет способствовать организация системы управленческого учета одновременно в лесохозяйственных учреждениях и в государственных производственных лесохозяйственных объединениях. Взаимосвязь участников такой системы представлена на рис. 1.

Основная часть. Вопросам организации управленческого учета как одной из подсистем учета в организации посвящены труды М. А. Вахрушиной, К. Н. Лебедева, Н. Е. Хинканиной, М. И. Петрачкова, С. И. Барановского, М. А. Толкачева и др. [1-5].

Вопросы организации бухгалтерского учета в лесном хозяйстве рассматривались в работах А. Н. Едошина [6], Б. В. Алахова, Н. А. Моисеева [7], В. А. Ильина, С. А. Новиковой, С. А. Ивашкевича [8], И. В. Самойлова [9], Э. К. Муруевой [10], Е. В. Павлова, В. А. Меньшиковой и др. Тем не менее отсутствует единая методика организации учета в лесхозах, учитывающая организационные, технологические и экономические особенности их деятельности.

В составе лесохозяйственных работ выделяются затраты, направленные на проведение рубок ухода, санитарных рубок, прочих рубок, и особенно в насаждениях, возраст которых старше 40 лет. Чем рентабельнее рубка, тем в большей степени проявляется коммерческий интеpec. В отношении таких видов рубок необходима особая и целенаправленная система учета затрат и продукции, т. е. система управленческого учета.
В условиях комплексного ведения лесного хозяйства, когда лесхозом как субъектом хозяйствования осуществляется коммерческая и лесохозяйственная (бюджетная) деятельность, рентабельные рубки неглавного пользования целесообразно приравнять (исходя из идентичности интересов) к лесозаготовкам по главному пользованию и, соответственно, вести учет в рамках промышленной деятельности организации [4].

В связи с необходимостью формирования оперативной информации для принятия управленческих решений в деятельности лесохозяйственных учреждений и в первую очередь для определения цены на древесину, полученную от рубок промежуточного пользования, осуществления оперативного контроля за движением финансовых потоков организации, а также осуществления калькулирования издержек на охрану окружающей среды, анализа хозяйственной деятельности необходимо организовать аналитический управленческий учет издержек по лесохозяйственной деятельности, расходов по рубкам промежуточного пользования и продукичи, полученной от них.

Обобщив исследования различных авторов, можно выделить основные этапы организации управленческого учета в лесхозе.

1 этап - подготовительный (организачионный). На данном этапе анализируется существующая система учета на предмет достоверности, полноты и оперативности предоставляемой информации [5], изучается действующая система документооборота, определяются основные задачи организации управленческого учета. При выполнении данного анализа следует учесть, что система управленческого учета должна решать только первоочередные задачи, а не охватывать всю деятельность лесхоза.

2 этап - оптимизация (технологический). Осуществляется согласование результатов первого этапа с существующей системой бухгалтерской информации (учетной политикой, рабочим планом счетов), разрабатывается учетная политика для целей управленческого учета, приобретается новое или корректируется существующее программное обеспечение учетного процесса.

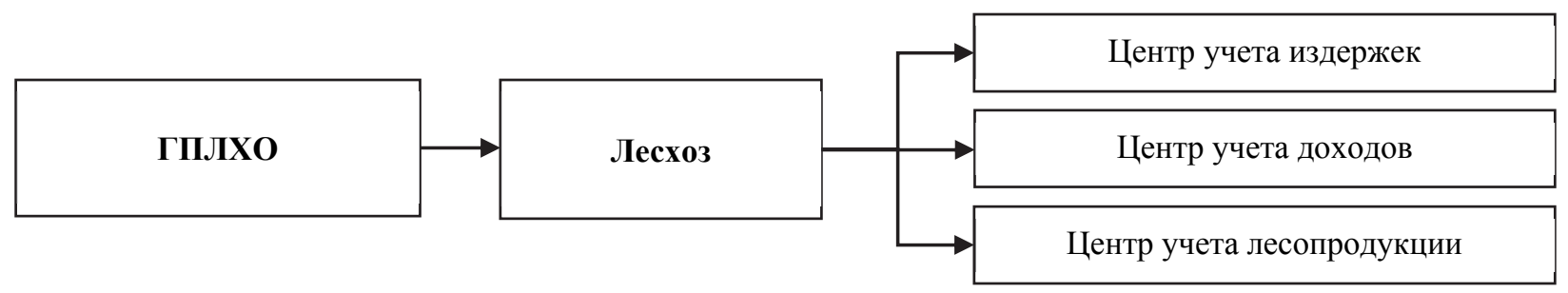

Рис. 1. Взаимосвязь участников управленческого учета 
3 этап-внедрение. Определяются структурные подразделения, в которых внедряется управленческий учет, и разрабатываются должностные инструкции работников, вовлеченных в процесс управленческого учета.

4 этап - подготовка управленческой отчетности. На данном этапе определяются формы отчетов и сводок, включающих информацию с любым уровнем детализации, устанавливается периодичность представления отчетности. Следует иметь в виду, что состав и порядок представления управленческой отчетности не регулируется нормативными и законодательными актами.

После определения целей организации управленческого учета с помощью бюджетов осуществляется процесс бюджетирования (планирования) по структурным подразделениям (центрам ответственности).

Основным плановым документом в лесхозе является производственная программа, которая составляется на предстоящий отчетный период с разбивкой на квартал, полугодие, 9 месяцев и в целом на год. Программа состоит из разделов в соответствии с видами работ (работы и услуги, оплаченные централизованно; лесохозяйственные работы; лесокультурные работы на землях гослесфонда; гидромелиоративные и лесоосушительные работы; лесозащитные работы; противопожарные мероприятия; общепроизводственные расходы; расходы на содержание лесохозяйственного аппарата (за исключением расходов на ведение охотничьего хозяйства); расходы на ведение охотничьего хозяйства; капитальные расходы).

В системе управленческого учета для получения оперативной информации о величине и составе доходов и расходов лесохозяйственного учреждения, а также сумме превышения расходов над доходами за отчетный период в сравнении с предыдущим отчетным периодом предлагаем составлять бюджет доходов и расходов, который даст возможность бухгалтеру-аналитику проанализировать результаты деятельности лесхоза в разрезе источников их получения и выполнить расчет прогноза деятельности. В целях оценки результатов деятельности данные в бюджете представляются не менее чем за два отчетных периода в сопоставимых ценах. В связи с динамично развивающейся рыночной ситуацией представление данных за более продолжительный период времени не всегда целесообразно. Для получения объективной информации о доходах и расходах данные бюджетов должны быть сопоставимы. Если данные за аналогичный период предыдущего года несопоставимы с данными за отчетный период, то их необходимо корректировать в зависимости от изменений учетной политики, законодательных и нормативных актов.

Кроме того, по бюджету возможно выполнить вертикальный и горизонтальный анализ. Вертикальный анализ позволяет выявить изменения в структуре затрат и доходов лесхоза, которые могут носить как позитивный, так и негативный характер. Для проведения вертикального анализа рассчитывается доля всех статей в общей величине доходов и расходов.

Горизонтальный анализ бюджета доходов и расходов предполагает оценку динамики роста отдельных статей. Стабильный рост доходных статей - это положительный момент в деятельности; причины увеличения затратных статей стоит оперативно анализировать.

Для проведения горизонтального анализа находится относительное изменение в процентах каждого показателя из бюджета по сравнению с предыдущим отчетным периодом. Данный анализ лучше всего проводить по годам за несколько лет для выявления долгосрочных тенденций в изменении определенных показателей.

Организационная структура, специфика деятельности, объемы выполняемых работ также имеют непосредственное отношение к организации управленческого учета [11]. Например, в качестве отдельных элементов управленческого учета могут быть выделены виды деятельности, разрешенные в соответствии с уставом:

1) лесохозяйственная;

2) лесозаготовительная;

3) производство топливных ресурсов и продукции побочного пользования.

Виды деятельности связаны между собой и не могут существовать обособленно друг от друга. Но, несмотря на это, процессы формирования издержек имеют свои особенности с учетом специфики хозяйственных процессов по каждому виду деятельности. Классификация издержек, степень их детализации и обобщения различаются в зависимости от особенностей хозяйственных процессов, происходящих в структурных подразделениях.

Аналитический управленческий учет можно организовать, используя организационную структуру управления с выделением центра издержек, центра доходов и центра учета лесопродукции, что даст возможность установить взаимосвязь между деятельностью структурных подразделений, ответственностью руководителей этих подразделений за результаты деятельности и общими результатами деятельности.

Центры ответственности являются объектами аналитического учета. Порядок обобщения расходов по лесохозяйственной деятельности аналогичен соподчиненности в организационной структуре организации. 


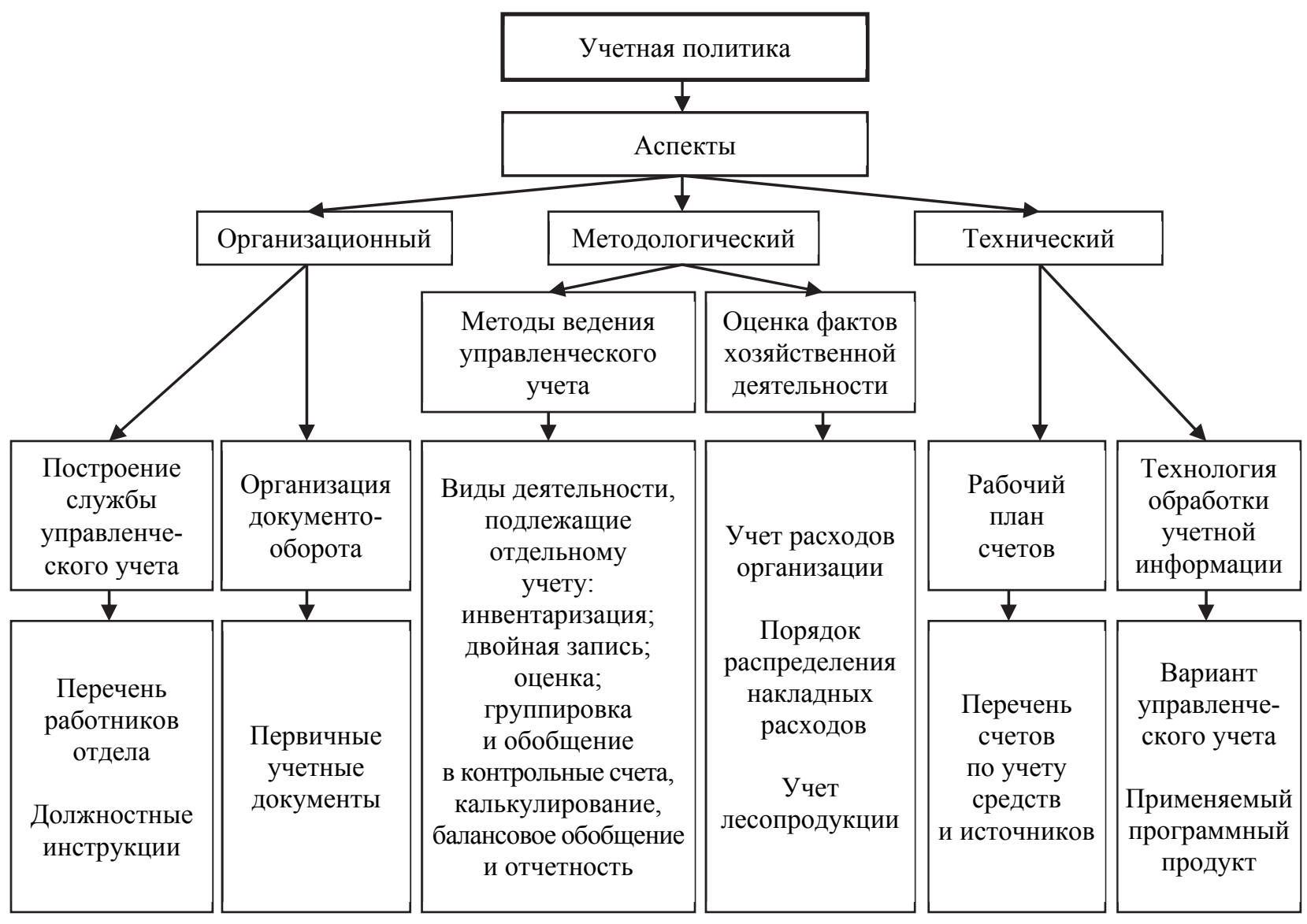

Рис. 2. Учетная политика в целях управленческого учета в лесохозяйственной организации

На основании анализа существующей практики учета доходов, расходов и лесопродукции осуществляется разработка учетной политики для целей управленческого учета.

Учетная политика для целей управленческого учета в лесохозяйственной организации представлена на рис. 2.

На основании изучения теории управленческого учета и сложившейся практики ведения аналитического учета в лесхозах возможно применение интегрированной системы с использованием варианта, ориентированного на организацию учета расходов по элементам. Связь финансового и управленческого учета осуществляется с помощью контрольных счетов, которые напрямую корреспондируют со счетами финансового учета [12].

При разработке плана счетов управленческого учета организации следует иметь в виду, что порядок отражения данных в первичном учете должен быть обусловлен принадлежностью издержек к определенному экономическому элементу и уточнять классификацию издержек по их видам и статьям калькуляции. Для этого необходимо организовать их учет по местам возникновения и выделенным центрам ответственности.
Финансовый и управленческий учет используют единую интегрированную систему счетов. В действующем в Республике Беларусь плане счетов бухгалтерского учета финансово-хозяйственной деятельности предусмотрен вариант, ориентированный на организацию учета затрат по элементам [13]. Для этого в плане счетов свободными остаются позиции 27, 28, 30-39.

$\mathrm{B}$ целях организации и ведения экологоориентированного управленческого учета предлагаем для учета расходов на проведение РПП и контроля за уровнем их общей величины, лесопродукции, полученной от их проведения, и экологических затрат использовать следующие счета:

- 37/1 «Расходы на проведение рубок промежуточного пользования» для отражения общей величины расходов на их проведение;

- 24 «Расходы по фазам лесосечных работ» (24/1 «Лесосечные работы», 24/2 «Вывозка леса») для группировки расходов по статьям калькуляции (в соответствии с организационной структурой) (местом возникновения расходов являются фазы лесосечных работ (валка, трелевка, раскряжевка, погрузка, разгрузка, сортировка, штабелевка));

- 25/4 «Общепроизводственные затраты лесопункта» для отражения общепроизводственных 
затрат по производственно-мастерским участкам (лесопунктам) лесохозяйственных учреждений;

- 27 «Экологические затраты» для учета текущих экологических расходов;

- 39 «Лесопродукция от РПП» для учета лесопродукции, полученной от рубок промежуточного пользования по фактической себестоимости.

Для учета расходов по элементам затрат в управленческом учете лесохозяйственного учреждения предлагаем использовать свободную позицию типового плана счетов бухгалтерского учета - счет 30 «Затраты лесохозяйственного учреждения» с выделением субсчетов к нему:

- 30/1 «Материальные затраты»;

- 30/2 «Затраты на оплату труда»;

- 30/3 «Отчисления на социальные нужды»;

- 30/4 «Амортизация основных средств и нематериальных активов»;

- 30/5 «Прочие затраты»;

- 30/6 «Общие затраты».

Аналитический учет на этих счетах ведут нарастающим итогом с начала отчетного года, а по его окончании все счета закрывают.

На следующем этапе по данным управленческого учета составляется внутренняя отчетность, которая является основанием для принятия управленческих решений, контроля деятельности, оценки качества работы руководителей структурных подразделений (центров ответственности). «Внутренняя отчетность - это совокупность упорядоченных показателей и другой информации. В ней дается интерпретация отклонений от целей, планов и смет, без чего управленческий учет остается формальным скоплением цифровых данных, непригодных для целей внутреннего управления» [14].

Внутренняя отчетность должна обеспечивать быстрый обзор и оценку фактических данных, их отклонений от плановых, определение существующих недостатков сегодня и на будущее, выбор оптимальных вариантов управленческих решений [14]. В процесс разработки системы отчетности могут быть вовлечены бухгалтеры-аналитики и руководители соответствующих центров ответственности, работники планово-экономического отдела и другие специалисты.

К основным требованиям к внутренней отчетности можно отнести: единообразие структуры, доступность информации, оптимальные сроки представления, наличие аналитической информации, возможность использования для анализа и контроля деятельности.

Доступность отчетной информации достигается отражением в отчетных формах только той информации, которая необходима руководителю конкретного структурного подразделения.
Оптимальность частоты представления внутренней отчетности зависит от необходимости принятия оперативных решений и предоставления дополнительных сведений.

В лесохозяйственном учреждении требования к внутренней отчетности по учету расходов по РПП и лесопродукции от них устанавливают руководители соответствующих центров ответственности - центра учета расходов и центра учета лесопродукции. При этом в систему управленческой отчетности могут быть включены следующие отчеты:

1) по лесохозяйственной деятельности:

- отчет по расходам на лесохозяйственные работы; боты;

- отчет по расходам на лесокультурные ра-

- отчет по расходам на гидромелиоративные и лесоосушительные работы; боты;

- отчет по расходам на лесозащитные ра-

- отчет по расходам на противопожарные мероприятия;

- отчет по общепроизводственным затратам;

- отчет по расходам на содержание лесохозяйственного аппарата;

- отчет по расходам на ведение охотничьего хозяйства;

- отчет по видам рубок;

- отчет о поступлении средств от реализации древесины в заготовленном виде;

- отчет по поступлениям от реализации древесины на корню.

2) по коммерческой деятельности:

- отчет о произведенной продукции;

- отчет по лесозаготовительному производству;

- отчет по РПП;

- отчет о реализации продукции;

- отчет по экспорту лесопродукции и услуг;

- отчет о дебиторской задолженности;

- отчет о кредиторской задолженности;

- отчет о движении денежных средств;

- отчет о финансовых результатах;

- сводный отчет.

В лесохозяйственном учреждении составление отчетности можно разбить на два этапа:

1 этап - составление отчетов первого уровня по определенному признаку или группе признаков (по направлениям расходов, по видам рубок, по фазам лесосечных работ с учетом накладных расходов). Срок их составления - еженедельно и ежемесячно;

2 этап - группировка данных отчетности первого уровня в сводные отчеты второго уровня в целом по лесхозу. Срок их составления от ежемесячных до ежегодных.

Необходимо отметить, что на основании анализа отчетных данных о проведении РПП 
представляется возможным принятие оперативных управленческих решений не только с точки зрения формирования высокопродуктивных насаждений, но и с точки зрения экономического аспекта данного вида рубок. Как уже было сказано, экономический эффект от проведения РПП может быть достигнут при переводе данного вида рубок в коммерческую деятельность лесхоза. При этом необходимо предостеречь лесохозяйственные учреждения от фактического превращения рубок ухода в условносплошные или им подобные рубки худшего вида [15].

На втором этапе группировки данных отчетности первого уровня в сводные отчеты второго уровня в целом по лесхозу возможно выявить отклонения от плана выполненного объема лесохозяйственных работ, а также обнаружить факторы, которые влияют на выполнение плановых показателей производственной программы.
После составления отчетности осуществляется управленческий контроль за выполнением планов со стороны руководства лесхоза и анализ его результатов. В лесхозе больший эффект достигается при проведении управленческого контроля с обратной связью, т. е. путем сравнения бюджетных и фактических результатов.

Управленческие решения принимаются на базе проведенного внутреннего управленческого контроля бюджетных форм и форм внутренней отчетности посредством проведения управленческого анализа по отдельным контрольным показателям.

Заключение. В целом можно сделать вывод, что организация и использование в лесохозяйственных учреждениях системы управленческого учета расходов на проведение РПП и лесоматериалов, полученных от них, обусловлены целесообразностью усиления системы учета и оценки лесного капитала и издержек, связанных с его воспроизводством.

\section{Список литературы}

1. Вахрушина М. А. Бухгалтерский управленческий учет. М.: Омега-Л, 2002. 528 с.

2. Лебедев К. Н. Роль данных бухгалтерского учета в управлении на предприятии: прошлое, настоящее и будущее // Международный бухгалтерский учет. 2016. № 24. С. 2-17.

3. Хинканина Н. Е. Управленческие аспекты бухгалтерского учета в лесном хозяйстве: дис. ... канд. экон. наук: 08.00.12. Санкт-Петербург, 2003. 185 л.

4. Неверов А. В., Боровская М. Е. Эколого-экономическая концепция управления издержками лесохозяйственного производства // Труды БГТУ. Сер. 5, Экономика и управление. 2021. № 1. С. 83-91.

5. Барановский С. И., Толкачев М. А. Совершенствование системы управленческого учета на предприятиях малого и среднего бизнеса // Труды БГТУ. 2016. № 7: Экономика и управление. C. 254-257.

6. Едошин А. Н. Бухгалтерский учет в лесном хозяйстве. М.: Лесная пром-сть, 1976. 376 с.

7. Моисеев Н. А. Экономика лесного хозяйства. М.: ГОУ ВПО МГУЛ, 2006. 384 с.

8. Ивашкевич В. Б. Бухгалтерский управленческий учет. М.: Экономика, 2004. 618 с.

9. Самойлов И. В. Организация бухгалтерского учета и налогообложение лесных хозяйств // Главбух. 1999. № 10. С. 22-31.

10. Муруева Э. К. Экологические аспекты бухгалтерского учета (на примере лесного сектора экономики): дис. ... канд. экон. наук: 08.00.12. Санкт-Петербург, 2007. 185 л.

11. Боровская М. Е. Управленческие аспекты бухгалтерского учета в лесном хозяйстве // Труды БГТУ. 2011. № 7: Экономика и управление. С. 167-169.

12. Друри К. Управленческий и производственный учет. М.: ЮНИТИ-ДАНА, 2006. 236 с.

13. Об установлении типового плана счетов бухгалтерского учета, утверждении Инструкции о порядке применения типового плана счетов бухгалтерского учета и признании утратившими силу некоторых постановлений Министерства финансов Республики Беларусь и их отдельных структурных элементов: постановление М-ва финансов Респ. Беларусь, 29 июня 2011 г., № 50 // Национальный правовой Интернет-портал Республики Беларусь. URL: https://normativka.by/lib/document/ (дата обращения: 10.09.2021).

14. Палий В. Ф. Управленческий учет издержек и доходов (с элементами финансового учета). М.: Инфра-М, 2006. 279 с.

15. Мелехов И. С. Лесоводство. М.: МГУЛ, 2003. 46 с.

\section{References}

1. Vakhrushina M. A. Bukhgalterskiy upravlencheskiy uchet [Management accounting]. Moscow, Omega-L Publ., 2002. 528 p.

2. Lebedev K. N. The role of accounting data in enterprise management: past, present and future. Mezhdunarodnyy bukhgalterskiy uchet [International accounting], 2016, no. 24, pp. 2-17 (In Russian). 
3. Khinkanina N. Ye. Upravlencheskiye aspekty bukhgalterskogo ucheta v lesnom khozyaystve. Dis. ... kand. ekon. nauk [Management aspects of accounting in forestry. Diss. PhD (Economics)]. St. Petersburg, 2003. 185 p.

4. Neverov A. V., Borovskaya M. E. Ecological and economic concept of managing the costs of forestry production. Trudy BGTU [Proceedings of BSTU], issue 5, Economics and Management, 2021, no. 1 (244), pp. 83-91 (In Russian).

5. Baranovsky S. I., Tolkachev M. A. Improving the management accounting system at small and medium-sized businesses. Trudy BGTU [Proceedings of BSTU], 2016, no. 7: Economics and Management, pp. 254-257 (In Russian).

6. Edoshin A. N. Bukhgalterskiy uchet v lesnom khozyaystve [Accounting in forestry]. Moscow, Lesnaya promyshennost' Publ., 1976. 376 p.

7. Moiseev N. A. Ekonomika lesnogo khozyaystva [Economics of forestry]. Moscow, GOU VPO MGUL Publ., 2006. 384 p.

8. Ivashkevich V. B. Bukhgalterskiy upravlencheskiy uchet [Management accounting]. Moscow, Ekonomika Publ., 2004. 618 p.

9. Samoylov I. V. Organization of accounting and taxation of forestry. Glavbukh [Chief accountant], 1999, no. 10, pp. 22-31 (In Russian).

10. Murueva E. K. Ekologicheskiye aspekty bukhgalterskogo ucheta (na primere lesnogo sektora ekonomiki). Dis. ... kand. ekon. nauk [Environmental aspects of accounting (on the example of the forest sector of the economy). Diss. PhD (Economics)]. St. Petersburg, 2007. 185 p.

11. Borovskaya M. E. Management aspects of forestry accounting. Trudy BGTU [Proceedings of BSTU], 2011, no. 7: Economics and Management, pp. 167-169 (In Russian).

12. Druri K. Upravlencheskiy $i$ proizvodstvennyy uchet [Management and production accounting]. Moscow, UNITI-DANA Publ., 2006. 236 p.

13. Ob ustanovlenii tipovogo plana schetov bukhgalterskogo ucheta, utverzhdenii Instruktsii o poryadke primeneniya tipovogo plana schetov bukhgalterskogo ucheta $i$ priznanii utrativshimi silu nekotorykh postanovleniy Ministerstva finansov Respubliki Belarus' $i$ ikh otdel'nykh strukturnykh elementov: postanovleniye Ministerstva finansov Respubliki Belarus', 29.06.2021, № 50 [On the establishment of a standard chart of accounts for accounting, approval of the Instruction on the procedure for applying a standard chart of accounts for accounting and invalidation of some decrees of the Ministry of Finance of the Republic of Belarus and their individual structural elements: Resolution of the Ministry of Finance of the Republic of Belarus, 29.06.2011, no. 50]. Available at: http://normativka.by/lib/document/ (accessed 10.09.2021).

14. Paliy V. F. Upravlencheskiy uchet izderzhek $i$ dokhodov (s elementami finansovogo ucheta) [Management accounting of costs and income (with elements of financial accounting)]. Moscow, Infra-M Publ., 2006. 279 p.

15. Melekhov I. S. Lesovodstvo [Forestry]. Moscow, MGUL Publ., 2003. 46 p.

\section{Информация об авторе}

Боровская Марина Евгеньевна - старший преподаватель кафедры экономики и управления на предприятиях. Белорусский государственный технологический университет (220006, г. Минск, ул. Свердлова, 13a, Республика Беларусь). E-mail: borovskaya.me@belstu.by

\section{Information about the author}

Borovskaya Marina Evgen'yevna - Senior Lecturer, the Department of Enterprise Economy and Management. Belarusian State Technological University (13a, Sverdlova str., 220006, Minsk, Republic of Belarus). E-mail: borovskaya.me@belstu.by 